\title{
Slow Learner Children Profiling for Designing Personalized eBook
}

\author{
Marzita Mansor, Wan Adilah Wan Adnan, and Natrah Abdullah \\ Faculty of Computer and Mathematical Science, \\ Universiti Teknologi MARA (UiTM), Malaysia \\ marzita@fskik.upsi.edu.my, \\ \{adilah, natrah\} atmsk. uitm. edu.my
}

\begin{abstract}
Advances in reading technology have created significant interest for young children to use eBook. But similar opportunity and enjoyable experience of using the eBook suit with slow learner needs seems to be impossible. This is due to the fact that the existing eBooks on the market are not designed to suit with the slow learner reading capability. This situation stimulates the desire to explore on the need to design a personalized eBook for slow learner children. This paper presents the findings of the interview session conducted on five slow learner children and a school teacher at one of the primary school in Malaysia in order to explore on the need to provide individual learning. It also presents an overview of the research approach and shares an initiative conducted to adapt Segmented Personalization and Scaffolding approach in the eBook application development. We do hope that this study able to provide an overview on the importance of providing personalized learning especially for individuals with learning disabilities.
\end{abstract}

Keywords: personalized, eBook, slow learner, reading.

\section{Introduction}

Personalization is found to have a great impact on education. In general, personalization of education aims at providing individualized learning which enables learners learn according to their uniquely identified personal, needs and learning content. However, the missing link in implementing the personalization dreams are due to heavy emphasizes on implementing personalization for normal students, but the individual needs and unique characteristic of students with special needs have been ignored. Motivated by this factor, this study aims to adapt the personalization touch in order to assist students with learning disabilities, the slow learners who have difficulties in reading by designing personalized eBook for their reading purposes. The reading difficulties of the slow learner children are chosen as one of the study phenomenon due to the fact that reading ability determine success or failure of the children (Musen, 2010) . Apart from that this study also chooses eBook application to be used as a learning tool embedded with the personalization touch and reliable principles 
related to reading in order to cover the slow learner children's need and suit with their profile. In this study, we see the potential of eBook due to increasing on its usage on the net and its capability and availability at anytime are some of eBook potentials.

As other learning technology, eBook also required personalization touch embedded in its interface design in order to assist readers, especially in the context of this study, the slow learner, in a more convenient way of reading. EBook, the electronic version of the printed book with the enhancement of the electronic features able to provide easily accessed to the reading materials worldwide. Although there is a positive reaction (Roskos \& Bruek (2009) on the eBook usage of young children, for one thing it could be argued that the studies on eBook is lack of discussion on design principles. Only several researchers see the importance of implementing book with design principles from theories (Barua, Kay, Kummerfeld, \& Paris, 2011) or framework in the area of design. There is also lack of studies related to eBook (Mckay, 2011)and limited evidence on any guideline principles for development of existing eBook discusses by academic scholars especially for special need children as the slow learner. Other than that, previous research has indicated that despite from the comeback of the eBook as reading technology, there are some unanswered questions in the eBook designing area. A study by (Beer \& Wagner, 2011) stated that eBook concepts also need some enhancement in the design process. Meanwhile, a study by (Colombo \& Landoni, 2011) and a survey conducted by the researcher during the Malaysian International Book Fair 2013 at Putra World Trade Centre (PWTC) Kuala Lumpur have proven that eBook available on the Malaysia are poor copied of translation of book in printed format and require a new design in order to take full advantage of eBook potentials. This paper presents two aspects; the user profile of the slow learner in order to show the need of personalized learning and presents a research approach of the eBook design process with the adaptation of segmented personalization and scaffolding approach.

\section{Related Works}

\subsection{The Implementation of eBook in Malaysia Context}

Although the new concept is not widely discussed and the study concerning the eBook is so limited, the benefit that the eBook can provide is undeniable. Several studies have pointed out the main advantages of eBooks compared to printed books. Advantages of eBook are a capability of quick navigation, meaning that eBook allows easy to jump between chapters; it offers bookmarks or highlighting features; eBook can be translated to any preferred language set by individual users (Beer \& Wagner, 2011) and also eBook found to be more responsive to user needs (McKay, 2011). Other than that, eBook provides a lot of benefit to its reader especially to slow 
learner children in term of language proficiency by improving children concentration, comprehension skills, increasing vocabulary and learning the eBook with the use of personal interaction and experience. Although the eBook is not widely used as an educational material in the classroom, the accessibility of the eBook which available across the border due to the availability to be purchased online be the most benefit to all. In Malaysia perspective, this new trend can be regarded as a positive impact to the slow learner children. The changing on the perspective of using the technology to fulfill children ample time with game activities may be shifted to the use of technology devices for reading purposes. IPad, laptop, handheld devices which are close to the heart of the generation Y children can be utilized to promote reading habits for slow learner children. In recent years, there has been an increasing interest in the eBook. It can be denied that an eBook has a lot of potentials. As mentioned before, the use of eBook in Malaysia environment is still new, especially related to learning materials for primary school children. A simple survey conducted by the researcher during the Malaysian International Book Fair 2013 at Putra World Trade Centre (PWTC) Kuala Lumpur, Malaysia has shown that although the price for eBook in Malaysia is not expensive compared to physical printed book of the same title, the eBook material is so limited. Most of the eBook offered in the exhibition is only for adult readers. The interface for eBook for children also has limited features and found to not be interactive. The interface only allows its user to change the font, the theme and adjust the screen size. Other that that the eBook promoted during this exhibition can only be considered as the direct translation of the printed book to the electronic version without any additional multimedia featured embedded in the eBook. During the informal interview that has been conducted, it is clearly stated by the eBook exhibitors, who are among the pioneers of the eBook industries in Malaysia, the implementation of the eBook is still limited. In addition to that, the researcher also questioned the exhibitor regarding the plain features of the eBook compared to the one that we can purchase from any other outside countries. The exhibitor honestly admitted the eBook is not widely used in Malaysia and the reading materials for slow learner children is so limited and still under progress on converting original printed materials into an electronic format.

\section{Research Approach}

The development of personalized eBook design for slow learner children requires a clear understanding of the characteristics of slow learner profiles, the intervention strategy and relevant personalization strategy and principle to be adapted in the eBook design. This session will discuss a research approach that has been conducted in order to come out with the personalized design of the eBook. 


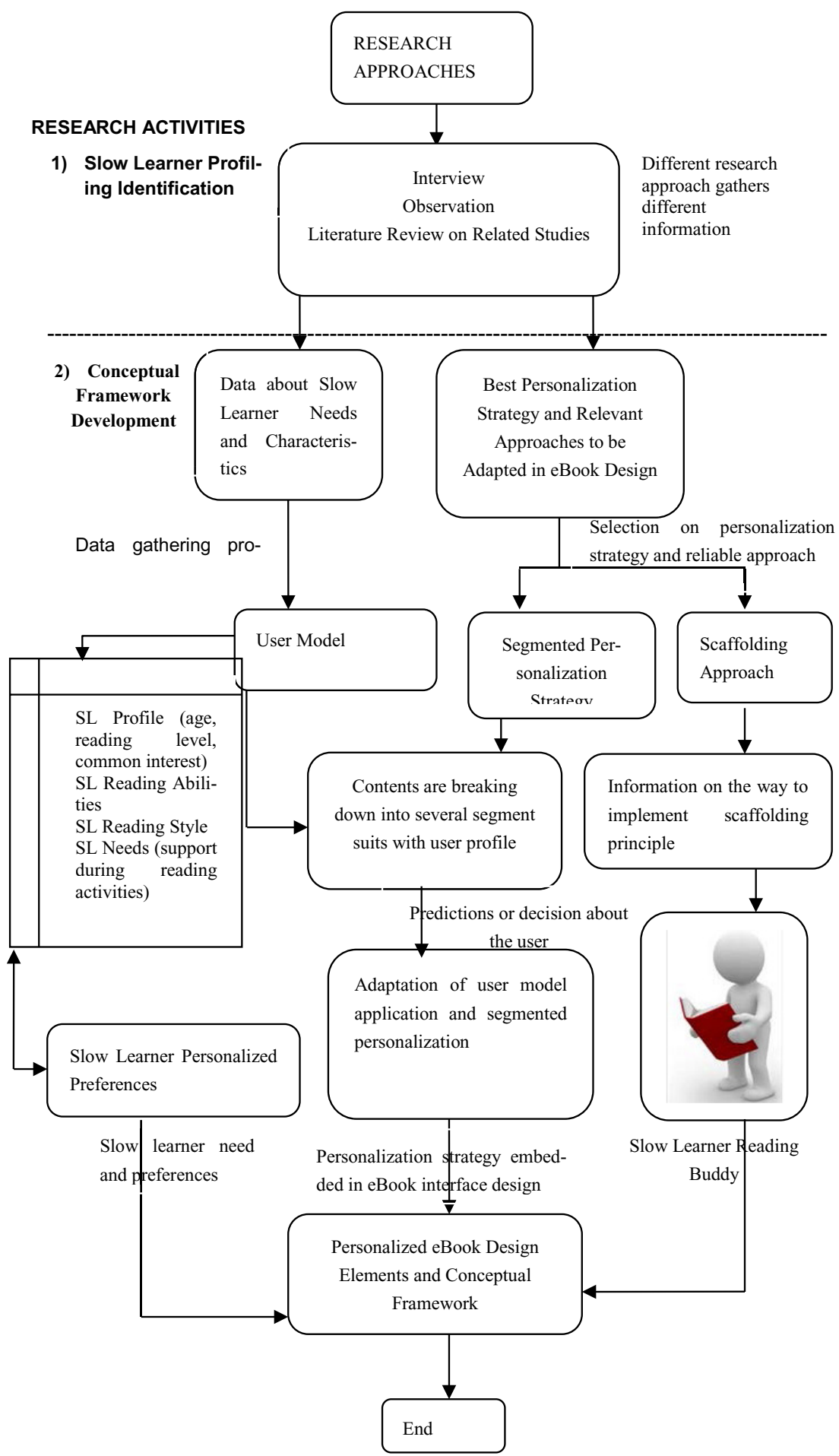




\section{$4 \quad$ Analysis and Result}

The slow learners are no longer a rare case in Malaysia and they are not categorized as people with special need. Being a slow learner means is that the student is unable to learn something in the amount of time assigned for the actual learning. (Vinci, 2009). Inability of slow learners to read also limits their capability to catch up with the learning process at school. Due to the inability of school authorities or even parent to recognize slow learner students at their early age, the slow learner students are allocated at the same classroom as normal students and both share the same syllabus, same teaching aids and approaches of teaching and learning style from the same teachers without considering their limited knowledge capability. Moreover, the standardization of learning material and learning content to every child in schools also do not give any privilege to slow learner children as the content of learning document provide a guideline of the learning content without looking at the individual differences in term of their cognitive ability and characteristics. The high level of knowledge which cannot be coped by their mental capability make a major problem to slow learner children as majority of slow learner children having difficulty in reading. Therefore, in order to cater the problem in providing the reading materials for the slow learner, the personalized eBook can be utilized as a learning tool which emphasizes on the individual need of each slow learner problems is introduced in this study. This study is undertaken with the specific intention to find the possible solution to slow learner children whom having difficulties in reading through the eBook personalization as a solution. By doing so, it is perhaps to ensure that the researcher fully understand whole aspects of these children before adapt the intervention solution with the introduction of personalized eBook application for the slow learner children. This study aims to involve slow learner children in exploring eBook as an alternative reading material which encompasses of interactive multimedia elements to attract their attention to learn reading through more engaging, usable and fun e-book interfaces for them. Thus, this study focuses on providing slow learner children with a new exposure of personalized eBook application setting and taking into account their reading ability and needs in a classroom. The respondents of the study consist of 5 slow learner children in a primary school in Malaysia and 2 slow learner teachers. The result of the data gathering process will be discussed in the next session presented in this paper.

\section{Slow Learner User Profile}

The preliminary investigation has been conducted twice in order for the researcher to have a look at the real problem happens in the classroom setting. With an intention to interact with the school teacher as well as the slow learner session, the researcher has sought permission from the school headmaster to see how the slow learner children at school learn. One hour session has been utilized with the interview, observation and interaction. The result learned from the investigation shows that the slow learner children who having difficulties in reading also have different characteristics. These results also illustrate the need to provide personalization approach as a solution that 
can cover the need of each individual user in reading aspect. Figure 1.0 shows the unique characteristics of each slow learner children in relation to their performance in reading.

\begin{tabular}{|c|c|c|c|c|c|}
\hline Name & Age & SL Need & $\begin{array}{l}\text { Reading } \\
\text { Ability } \\
\text { based on } \\
\text { Construct } \\
\text { (School } \\
\text { Assess- } \\
\text { ment) }\end{array}$ & $\begin{array}{l}\text { Reading Abil- } \\
\text { ity Level }\end{array}$ & $\begin{array}{l}\text { Reading } \\
\text { Style }\end{array}$ \\
\hline & $\begin{array}{l}8 \text { years old/ } \\
\text { Girl/ } \\
\text { Malay }\end{array}$ & $\begin{array}{l}\text { Need repeti- } \\
\text { tion and read- } \\
\text { ing compan- } \\
\text { ion }\end{array}$ & Construct 2 & $\begin{array}{l}\text { Able to read } \\
\text { up to } 2 \text { sylla- } \\
\text { bles, able to } \\
\text { read but do not } \\
\text { able to under- } \\
\text { stand what } \\
\text { have been } \\
\text { read. }\end{array}$ & $\begin{array}{l}\text { Interested } \\
\text { with reading } \\
\text { exercise } \\
\text { using toys } \\
\text { and game } \\
\text { instead of } \\
\text { using book. }\end{array}$ \\
\hline & $\begin{array}{l}8 \text { years old/ } \\
\text { Boy/ } \\
\text { Indian } \\
\text { Muslim }\end{array}$ & $\begin{array}{l}\text { Need repeti- } \\
\text { tion and read- } \\
\text { ing compan- } \\
\text { ion }\end{array}$ & Construct 4 & $\begin{array}{l}\text { Able to sound } \\
\text { closed sylla- } \\
\text { bles }\end{array}$ & $\begin{array}{l}\text { Prefer an } \\
\text { individual } \\
\text { attention, } \\
\text { prefer to } \\
\text { learn using } \\
\text { ICT }\end{array}$ \\
\hline & $\begin{array}{l}8 \text { years old } \\
\text { / Boy/ } \\
\text { Indian } \\
\text { Muslim }\end{array}$ & $\begin{array}{l}\text { Need repeti- } \\
\text { tion and read- } \\
\text { ing compan- } \\
\text { ion }\end{array}$ & Construct 6 & $\begin{array}{l}\text { Able to read } \\
\text { and write } \\
\text { words with } \\
\text { 'ng' closed } \\
\text { syllables. }\end{array}$ & $\begin{array}{l}\text { Prefer to } \\
\text { learn using } \\
\text { ICT. }\end{array}$ \\
\hline & $\begin{array}{l}8 \text { years old } \\
\text { / Boy/ } \\
\text { Chinese }\end{array}$ & $\begin{array}{l}\text { Able to read } \\
\text { with minimum } \\
\text { supervision }\end{array}$ & Construct 12 & $\begin{array}{l}\text { Able to read } \\
\text { and understand } \\
\text { stimulation } \\
\text { material }\end{array}$ & $\begin{array}{l}\text { Prefer to } \\
\text { learn using } \\
\text { ICT. }\end{array}$ \\
\hline $\mathrm{J}$ & $\begin{array}{l}8 \text { years old/ } \\
\text { Girl/ } \\
\text { Indian }\end{array}$ & $\begin{array}{l}\text { Able to read } \\
\text { with minimum } \\
\text { supervision }\end{array}$ & Construct 12 & $\begin{array}{l}\text { Able to read } \\
\text { and understand } \\
\text { stimulation } \\
\text { material }\end{array}$ & $\begin{array}{l}\text { Prefer to } \\
\text { learn using } \\
\text { ICT. }\end{array}$ \\
\hline
\end{tabular}

*Pseudonyms have been used for the students' name mentioned in this paper.

\section{Segmented Personalization Strategy for eBook Development}

By definition, personalization is a process that has a potential to provide a solution on providing reading materials according to individual needs and preferences. The reading material which has its own target reader can be customized or represented into more understandable, attractive and able to increase user's motivation, especially for 
the beginning reader who has variation in learning style and unique characteristics as an individual. Personalization has proven to be an effective tool in education fields. A number of studies conducted by (Tsianos, Germanakos, \& Lekkas, 2010)(Siadaty, 2008)(Brom, Bromová, Děchtěrenko, Buchtová, \& Pergel, 2013) has shown the effective way in which the personalization proven to be an effective way to maximize the learning process in order to achieve the optimum way of learning. The one-size-fitsall approach in reading can be defined as a way of reading where by ignoring the uniqueness of individual characteristics, behavior, knowledge, experience, learning style and level of thinking, the same reading materials are used by everyone who looking at the subject or topics. This traditional way of reading do not focus on the individual needs, previous knowledge of the reader as long as the reading activity can be performed. Instead, the personalization process taken care of all aspects of reading, including the user or reader profile which consists of the readers demographic information, knowledge and ability; the categorization of the knowledge to be transferred to the reader according to readers need in order to ensure that the transformation of knowledge performed in an efficient and effective order. Personalization of reading activity that considers the variety of reader characteristics able to generate new knowledge in the readers' mind faster that the traditional reading materials which can be considered as one-size-fits-all approach. The outcome of the study is hoped able to provide a broad picture on the need to provide specific guidelines in order for us to understand the uniqueness of slow learner children and to provide a suitable personalized reading tool for them. By doing so, it will ensure that the material use of teaching and learning suit with the capability of slow learner children as an alternative for one-size-fits-all approach as implemented in the real classroom setting. Another possibility is that by providing an eBook as an extra alternative reading tool perhaps we will be able to cater slow learner problems in relation to reading difficulties as reading is a gateway to future success in school and in life (National Institute for Literacy, 2007). Again, the designing aspect of the user interface of an eBook is a part of the study, which concern on the personalization aspects that might be useful in helping slow learner children read better as it provides the solution based on the individual need of each young child.

According to Martinez (2011) Segmented Personalization is one type of personalization strategy that uses demographics, common attributes, or surveys to group or segment learning populations into smaller, identifiable and manageable groups. In the personalization, the users are being segmented into different group a common characteristic they have shared. This study proposes the use of the segmented personalization strategy in order to categorize the slow learner children into several suitable categories. Then after the categories have been identified, the personalization strategy will be adapted to the development of the personalized eBook for the slow learner children. . In a survey conducted and explained in figure 1.0, we can conclude that several segments have been categorized based on the slow learner common characteristics, ability and need as follows:

- Slow Learner Common characteristics: age, gender, preference on topic or subject

- Reading Ability Level (Determine by construct: Reading Achievement) 
- Slow Learner Need (Repetition, Reading Style: read alone/ Scaffolds, Categories: Beginner, intermediate, advance Slow Learner)

\section{$7 \quad$ Scaffolding Approach for Slow Learner Children}

The Scaffolding Theory is the theory commonly uses in the education area. As the name implies scaffolding theory promotes the assistive learning for the children as an assistant that can help the children throughout the learning processes. The initial idea Of Scaffolding grew out of Vygotsky's work and then the concept then is expanded into the Scaffolding theory developed by the Psychologist, Jerome Bruner. The Scaffolding Theory is a theory implies the technique of assisting children to learn by providing the learning tools and then after the children master at a certain level, the assistance will be gradually withdrawn in order to allow the children learn language independently. In this study the concept of scaffolding is embedded in the artifacts developed in this study, not only in the instantiation in a form of eBook, but also in the proposed conceptual framework and guidelines. The Scaffolding Theory is chosen to be embedded in this research due to its capability in providing assistance to the special needs children who have difficulties in reading. The idea of scaffolding is consistent with the Zone of Proximal Development (ZPD) suggested by Vygotsky (1978) which describe the importance of achieving Zone of Proximal Development in the learning process. In general, the ZPD focus on understanding current level of a child's achievement and provide support (scaffold) in the learning process in order to enhance the child's potential in learning activities. The ZPD suggests that the learner can achieve an understanding of the knowledge beyond they expected with the use of scaffolding which describe the importance of providing support for the student in the learning process. The feel of boredom and anxiety can be minimized with the assistance of the scaffolding whether it relates to the existence of a human, tool or technology.

The concept of scaffolding allows the slow learner to learn reading based on their need. The scaffolding assists the slow learner during the reading activities until they have mastered certain level which shows they can learn reading on their own. At the first stage of the learning process, the reading activities begin when the teacher does the demonstration to the slow learner on how to read by introducing the read aloud activities. This process considers slow learner as a beginner. At this stage, the teacher chooses suitable material for teaching purpose. After the slow learner has shown their interest to learn and voluntarily want to participate in the reading activities, the teacher can change their role from a demonstrator to the reading partner by sharing reading material with the slow learner in an enjoyable manner. The process continues, and after the slow learner able to read on their own, the slow learner is allowed to learn independently and they also can choose their own reading materials. The scaffolding concepts indirectly guide and encourage the slow learner during the reading process, and after the slow learner has shown some improvement, they are allowed to perform an independent reading. The concept of scaffolding is suitable to be adapted in the reading technology as an eBook. The interactive reading buddy suggested by 
the scaffolding concept able to grasp the slow learners attention and perhaps able to provide an opportunity to make them learn reading in a most enjoyable manner.

\section{Conclusion}

In general, personalization idea promises to provide individual learning to each individual learner. Despite limited studies on the implementation of the personalization to learner with learning disabilities, we see that the concept of personalization is ideal to be implemented in the educational field, especially when dealing with the slow learner children who have limited abilities in literacy skills, especially in reading. This study reveals the difference characteristics of the slow learner from the preliminary investigation conducted. Other than that, the concept of the personalization also has a potential in assisting slow learner difference characteristics, variation in reading ability, reading style and needs. In conclusion, apart from that the exploration on the relevant principle, the scaffolding, this study also provides the benefit for the researcher in understanding in depth on the implementation of the personalization which not only require the information technology related strategy or approach, but also need more consideration beyond that which includes an adaptation of other related principles.

\section{References}

1. Barua, D., Kay, J., Kummerfeld, B., Paris, C.: Theoretical foundations for user-controlled forgetting inscrutable long term user models. Theoretical foundations for user-controlled forgetting inscrutable long term user models (2011),

http: / / dl .acm.org/citation. cfm?id=2071541 (retrieved)

2. Beer, W., Wagner, A.: Smart Books - Adding context-awareness and interaction to electronic books, pp. 5-7 (2011)

3. Brom, C., Bromová, E., Děchtěrenko, F., Buchtová, M., Pergel, M.: Personalized Messages in a Brewery Educational Simulation: Is the Personalization Principle Less Robust than Previously Thought? Computers \& Education (2013), doi:10.1016/j.compedu.2013.11.013

4. Colombo, L., Landoni, M.: Towards an engaging e-reading experience. In: Proceedings of the 4th ACM Workshop on Online Books, Complementary Social Media and Crowdsourcing - Books Online 2011, p. 61 (2011), doi:10.1145/2064058.2064074

5. Landoni, M.: Ebooks children would want to read and engage with. In: Proceedings of the Third Workshop on Research Advances in Large Digital Book Repositories and Complementary Media - BooksOnline 2010, p. 25 (2010), doi:10.1145/1871854.1871862

6. Mckay, D.: A jump to the left (and then a step to the right): Reading practices within academic ebooks (2011)

7. Musen, L.: I N D I C AT O R Early Reading Proficiency (May 2010)

8. National Institute for Literacy. Early Literacy: Leading the Way to Success (2007)

9. Siadaty, M.: E-Learning: From a Pedagogical Perspective 6(2), 99-117 (2008) 
10. Tsianos, N., Germanakos, P., Lekkas, Z.: Working memory span and e-learning: The effect of personalization techniques on learners' performance. ..., and Personalization (2010),

http: //link.springer.com/chapter/10.1007/978-3-642-13470-8_8 (retrieved)

11. da Vinci, L.: Slow learners, pp. 1-8 (2009)

12. Vygotsky, L.: Thought and Language, trans. A. Kozulin. Harvard University Press, Cambridge (1934/1986)

13. Wilhelm, J., Baker, T., Dube, J.: Strategic Reading. Heinemann, Portsmouth (2001) 